\title{
Functional bread enreached with regional bioactive food additives
}

\author{
A. S. Khamitsaeva ${ }^{1}, V . V$. Sadovoy ${ }^{1}, Z$. G. Ramonova ${ }^{1}, P . N$. Semenov $^{1}, A . O$. Nartikoeva ${ }^{2}$, \\ E. S. Dzodzieva ${ }^{1}$, V. A. Gasieva ${ }^{1}, Z$. S. Khamitsaeva ${ }^{1}, V$. Kh. Sebetov ${ }^{1, *}$, and $S . F$. Zokoeva ${ }^{2}$ \\ ${ }^{1}$ Gorsky State Agrarian University, Vladikavkaz, Russia \\ ${ }^{2}$ North Ossetia State University named after K.L. Khetagurova, Vladikavkaz, Russia
}

\begin{abstract}
The scientific work presents materials of theoretical and experimental substantiation of the use of regional bioactive food additives, namely wild plants of the legume family (Fabaceae), permitted for use in the food industry: sweet clover (Melilotus officinalis), red meadow clover (Trifolium pratense), white acacia (Robinia pseudoacacia) in the production of functional foods [1]. Experimental studies of the safety indicators of food wild-growing plants (FWP) have been carried out. It was found that the studied FWP growing in ecologically clean areas of the North Ossetia-Alania are distinguished by a low mass fraction of toxic substances. Two fractions of cellulose were investigated: 1 - water-soluble (pectic acid, pectin, methylcellulose); 2 - water-insoluble (protopectin, cellulose, hemicellulose). The increased content of dietary fiber in WGP powders has been established, corresponding to the physiological norms of satisfying the daily requirement for FWP and, in this regard, indicating the expediency of using functional food in formulations for the prevention and treatment of diabetes mellitus, obesity, and atherosclerosis. The sorption capacity of WGP powders with respect to lead has been investigated. All studied powders of WGP modification products are characterized by high sorption capacity. The technologies of flour products with the addition of FWP powders have been developed. The results of clinical and preclinical studies of the developed functional bread show a corrective effect of glycemic blood parameters, as well as a decrease in the lead content in the blood of fed laboratory rat pups by almost two times, compared with the control.
\end{abstract}

\section{Introduction}

The purpose of this work was to expand the scope of using regional food wild-growing plants in the technology of functional flour products, which has not only scientific, practical and technological foundations, but also an important social argument in improving the human body. Fortified food products, including dietary fibers of medicinal wild plants, can prevent diseases caused by the anti-alimentation factor of nutrition, as well as harmful impurities in the environment.

Tasks to achieve this goal were set:

\footnotetext{
*Corresponding author: sebet2009@yandex.ru
} 
- to perform theoretical substantiation of the FWP use in the production of functional flour products;

- to substantiate the choice of food wild-growing plants, to assess the technological and nutritional adequacy;

- to study the safety indicators of wild plants;

- to investigate the polysaccharide composition of FWP powders;

- to determine the sorption capacity of food wild plants;

- to investigate the sorption capacity of the developed flour products on laboratory animals;

- to investigate the glycemic profile of the developed functional bread with FWP in volunteer patients.

\section{Methods and materials}

Objects for development were selected according to their food, technological adequacy, resource availability, prevalence in the North Ossetia region.

Powders of dried wild-growing plants (red meadow clover flowers, red meadow clover leaves, white acacia flowers, sweet clover flowers, sweet clover leaves), as well as finished flour products were selected as objects of research.

The safety indicators of raw materials and finished products were investigated by atomic absorption spectrometry according to GOST 26932-86; GOST 32163-2013 - Food products. Method for determination of strontium content is Sr-90; mycotoxins - according to GOST R 50474-93 - Food products. Methods for the detection and determination of the number of bacteria of the group of Escherichia coli (coliform bacteria).

Soluble and insoluble polysaccharides in FWP powders were determined in accordance with: MUK 4.1.1596-03, patent 2434532 "Method for determining the mass fraction of pectin substances in plant raw materials" [7, 11].

Dietary fibers were investigated in a sulfuric acid medium with a colorimetric determination of the colored product by comparing the color intensity or light absorption of the test solution and the standard with a known content of the analyte.

The sorption efficiency of heavy metal salts by ballast substances was investigated using a modified technique.

Preclinical studies of laboratory rat pups biomaterials were carried out using methods on ARCHITECT 8000.

The change in the physicochemical indicators of the quality of FWP was assessed by the dynamics of the content of the polysaccharide composition of food wild-growing plants, with the aim of using them in the production of functional food products to enrich the composition of flour products with protective components. For the preparation of powders of edible wild plants, the aerial parts of the selected FWP objects (leaves, stems, inflorescences), collected in the Alania region in 2018-2020 during the flowering phase, dried according to the generally accepted technology, were used.

The importance of the research goal is within the framework of the "Concept of state policy in the field of healthy nutrition of the population of Russia", because one of the most important directions is indicated: "The development of new technologies for the production of food products with a directed change in the chemical composition should correspond to the needs of the human body, including to prevent various diseases, reducing the risk of exposure to harmful substances" $[9,11,13]$.

A significant role in the technology of functional food products is assigned to flour products, which are the most affordable food products from the standpoint of the cost factor, consumed every day by all groups of the population of the Russian Federation. 
To expand the range of functional flour products, it is important to introduce natural biologically active additives (BAA) into the formulations and not to use artificial fillers.

The results of such scientific research, associated with the use of biologically active additives, can guarantee the receipt of food products of valeological orientation.

Effective and expedient both from a practical-technological and from an ecological point of view to improve the quality of food products is the use of food wild plants rich in biologically active substances $[6,8,11]$.

As a dietary supplement for enriching the composition of the most common food products, including bakery products, rich plant raw materials of the Alania region, modified in properties and composition, can be used, in contrast to synthetic food additives used all over the world.

The theory of rational and optimal nutrition - to ennoble the internal state of a person, at the level of the disease state of the population, it is possible by introducing such biological factors as enterosorbent, antioxidant, etc. into food products [2, 10, 12].

The study object of trophology is the general laws of assimilation of essential nutrients at all stages of any block of living systems.

The issue of impeccable food and optimal nutrition, coordination and measures of food production technologies based on trophological considerations refers to an applied problem, taking into account the peculiarities of the biosystem, the spare parts from it are only in the surrounding nature, in view of this, wild plant living systems were selected for use in development functional bread technology [2].

The products under development can take an extreme position between functional and traditional medicine, since health-improving products, providing homeostasis, regulating redox reactions, will become a means of general, prophylactic, therapeutic action $[2,4,5$, $14]$.

\section{Results}

Wild plant raw materials were modified using gentle convective drying, taking into account not only the intensity of moisture evaporation, but also the need to preserve the original composition of the biologically active substances.

In the course of drying, the mass fraction of moisture of the studied plant material was determined, taking into account which the moisture content $\omega(\%)$, calculated according to formula 1:

$$
\omega=\frac{W}{M_{C}} \cdot 100
$$

where $\mathrm{W}$ - sample moisture content, $\%$;

$\mathrm{M}_{\mathrm{c}}$-absolutely dry matter content, $\%$.

The amount of evaporated moisture $\mathrm{W}_{\text {и }}$ in the process of drying the FWP was determined by the formula 2 :

$$
\mathrm{W}_{\mathrm{u}}=\mathrm{M}_{1} \cdot \frac{\mathrm{W}_{1}-\mathrm{W}_{2}}{100-\mathrm{W}_{2}}
$$

where $\mathrm{M}_{1}$ - mass before drying;

$\mathrm{W}_{1}$ - moisture before drying, \%;

$\mathrm{W}_{2}-$ moisture at time $\tau$ during drying, $\%$.

Conversion of moisture content was carried out according to the formula 3:

$$
w=\frac{100 \cdot \omega}{100+\omega}
$$


The moisture characteristics of fresh wild-growing raw materials are given in Table 1.

Table 1. Moisture characteristics of fresh FWP

\begin{tabular}{|l|l|l|l|l|}
\hline Raw materials & $\mathrm{W}, \%$ & $\mathrm{M}_{\mathrm{c}}, \%$ & $\omega, \%$ \\
\hline \multirow{2}{*}{ Red meadow clover } & Inflorescences & 89,90 & 10,20 & 900 \\
\cline { 2 - 5 } & Stems, leaves & 91,40 & 8,60 & 877 \\
\hline \multirow{2}{*}{ Sweet clover } & Flowers & 89,77 & 10,23 & 820 \\
\cline { 2 - 5 } & Leaves & & & 784 \\
\hline White Acacia & Flowers & 90,7 & 11,3 & 880 \\
\hline
\end{tabular}

\section{Kinetic curves of the wild-growing raw material drying}

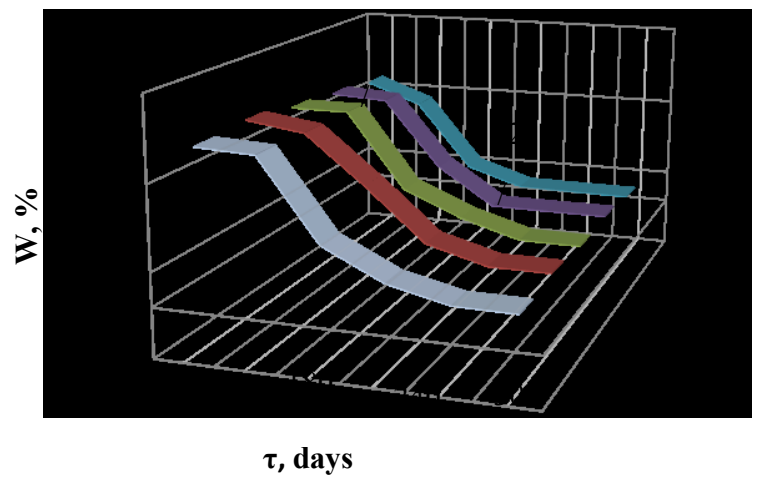

- Red Clover Inflorescences

- Red Clover Stems

and Leaves

- Sweet Clover

Flowers

- Sweet Clover

Leaves

White Acacia

Flowers

Fig. 1. Drying curves of the studied wild-growing raw material

The intensity of drying of wild plants is determined only by the parameters of the drying agent and does not depend on the moisture content of the dried material and its physicochemical properties.

The established parameters of the modes of heat treatment of food wild plants (FWP) characterize the preservation of the vitamin, mineral, polysaccharide composition and, as a consequence, increase the quality of the dried FWP.

Dried inflorescences, leaves, and stems of edible wild plants (FWP) were homogenized before turning them into flour on a roller mill. Dried wild plant flour is a finely ground powder. The degree of particle size reduction reached from 40 to 60 microns.

In order to obtain environmentally friendly products, the safety indicators of FWP were studied.

The obtained research data showed that the content of toxic substances in the FWP is below the permissible limit concentration, and this makes it possible to recommend the selected objects as environmentally friendly dietary supplements for inclusion in the formulations of functional flour products.

Indigestible carbohydrates of FWP powders are effective adsorbents, susceptible to bind and remove heavy metals from the body, and also have a great potential for use in the treatment of gastrointestinal and cardiovascular diseases.

In view of this, the content of dietary fiber in the obtained modified FWP powders was investigated (Table 2). 
Table 2. Content of dietary fiber in FWP powders

\begin{tabular}{|l|l|l|l|l|l|}
\hline \multirow{2}{*}{ Indicator } & \multicolumn{4}{l}{ Mass fraction, \% } & $\begin{array}{l}\text { White } \\
\text { Acacia }\end{array}$ \\
\cline { 2 - 6 } & \multicolumn{2}{|l|}{ Red Meadow Clover } & \multicolumn{2}{l|}{ Sweet Clover } & Flowers \\
\cline { 2 - 6 } & $\begin{array}{l}\text { Infloresce } \\
\text { nces }\end{array}$ & $\begin{array}{l}\text { Leaves } \\
\text { stems }\end{array}$ & Flowers & Leaves & \\
\hline Alimentary fiber & 7,9 & 8,3 & 11,3 & 7,7 & 9,7 \\
\hline Methylcellulose & 7,5 & 6,0 & 5,7 & 4,9 & 6,6 \\
\hline Pectin & 4,7 & 3,8 & 6,9 & 5,7 & 7,9 \\
\hline Pectic acid & 8,5 & 10,9 & 9,3 & 9,9 & 11,6 \\
\hline Protopectin & 10,5 & 12,7 & 9,3 & 8,9 & 9,6 \\
\hline Cellulose & 7,2 & 8,7 & 7,3 & 6,3 & 9,6 \\
\hline Hemicellulose &
\end{tabular}

According to the data from the Table 2, wild plants (red meadow clover, sweet clover, white acacia) are characterized by a significant content of dietary fiber, both soluble and insoluble.

Increased content of dietary fiber in FWP powders: inflorescences, leaves, stems of red meadow clover; flowers, leaves of sweet clover; flowers of white acacia; in accordance with the physiological norms of satisfying the daily requirement for alimentary fiber indicate the advisability of using functional food in formulations for the prevention and treatment of diabetes mellitus, obesity, atherosclerosis.

As mechanical stimuli alimentary fiber stimulate secretion, motility, the formation of gastrointestinal hormones, slow down the rate of food digestion, and these properties can help people control appetite, blood sugar levels in the body.

The sorption capacity of FWP powders with respect to lead was investigated (Fig. 2).

\section{Sorption capacity, \%}

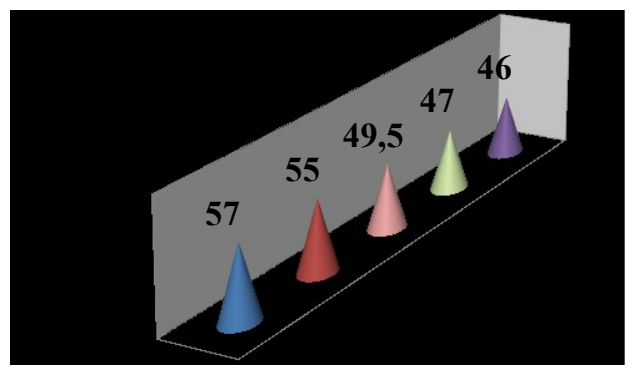

- White Acacia Flowers

- Red Clover Leaves

- Sweet Clover Leaves

" Sweet Clover Flowers

a Red Clover Inflorescences

Fig. 2. Sorption capacity of powders of edible wild-growing plants in relation to lead, $\mathrm{Pb}$

Finely ground powders of the FWP modification products showed a high enterosorbent capacity in relation to lead.

The line of efficiency of the studied FWP samples was revealed. A diagram of the sequence of decreasing $\mathrm{Pb}$ sorption capacity of FWP is presented: flowers of white acacia $\rightarrow$ leaves of red meadow clover $\rightarrow$ leaves of sweet clover $\rightarrow$ flowers of sweet clover $\rightarrow$ inflorescences of red clover.

The final results show broad possibilities of promising use for FWP modification products as enriching additives in the formulations of functional flour products.

Preclinical studies were carried out to study the sorption capacity of the developed functional bread. The results of studies of the physiological value are presented in table. 3 . 
Table 3. Study of the physiological value of functional bread with FWP

\begin{tabular}{|l|l|l|}
\hline Flour products: & $\begin{array}{l}\text { Lead content in blood, mg/l } \\
\text { at the beginning of the } \\
\text { experiment }\end{array}$ & $\begin{array}{l}\text { Lead content in blood, } \\
\mathrm{mg} / \mathrm{l} \text { the end of the } \\
\text { experiment }\end{array}$ \\
\hline Control & 2,79 & 2,30 \\
\hline Bread enriched with the FWP powders & 2,90 & 1,47 \\
\hline
\end{tabular}

Laboratory white rats were systematically feed for 28 days with a certain volume of flour products with FWP; compared with the control, they showed almost twice lower lead content in their blood.

Comparative analysis showed a pronounced therapeutic, functional sorbing effect of the developed bread with the addition of FWP.

The core device for the sorption of polysaccharides is their ability to waste and reduce the toxic effect of harmful substances.

The bioprotective and detoxifying properties of FWP, which include dietary fiber in physiologically standard doses, indicate an increase in the nutritional value of the developed functional bread and correspond to the preventive effect.

As powerful enterosorbents, they remove toxins and excess cholesterol from the gastrointestinal tract, regulate the glycemic profile, and are a substrate for the development of normal intestinal microflora.

Clinical and biochemical studies of the effectiveness of the action of functional bread on glycemic indicators (GI) were carried out.

A recruitment of patients was organized with some complaints of low increases in blood sugar levels in volunteers. All women were between the ages of 40 and 55.

In clinical trials, 28 respondents (volunteers), divided into 3 groups, took part; the first group (10 people) tested a new type of bread with the addition of FWP powders; the second group (10 people) - consummated traditional bread without functional additives; the third group ( 8 people) - according to research were treated with $50 \mathrm{~g}$ of pure glucose, measured blood sugar levels of these 8 patients are average.

The first experimental group of volunteers ate bread with a functional additive on an empty stomach in the amount of $145 \mathrm{~g}$, the second group ate traditional bread without functional additives in the amount of $140 \mathrm{~g}$, the third group or control consumed $50 \mathrm{~g}$ of pure glucose.

After consuming the studied bakery products every 15 minutes for the first hour and then every half hour, blood tests were taken to determine the level of sugar.

Based on the results of the analyzes, a graph of the blood sugar level after consumption of the test samples was compiled using a computer (Fig. 3). These graphs were compared with the analysis graph after consumption of $50 \mathrm{~g}$. 


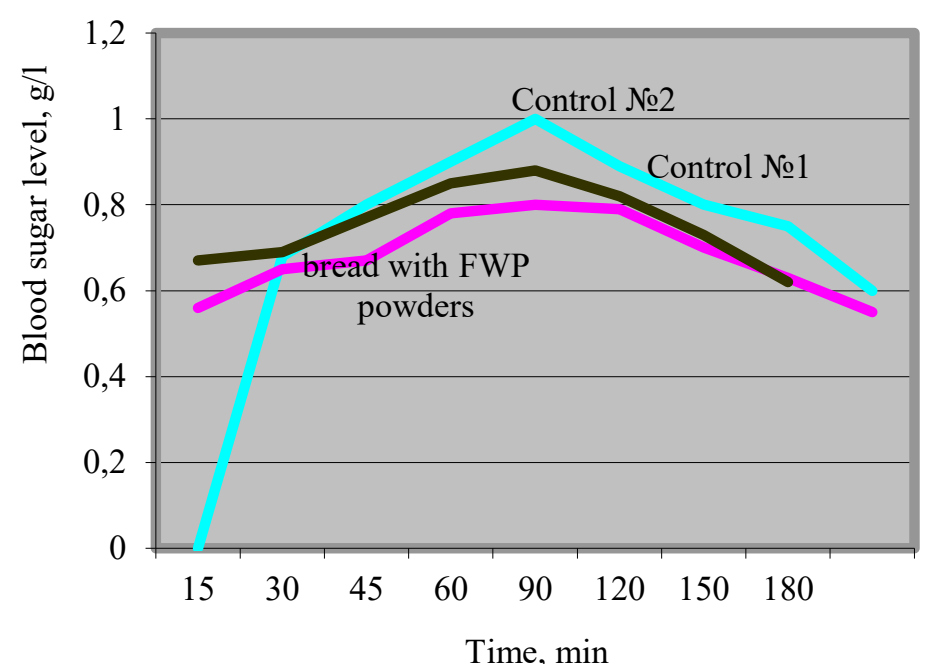

Time, $\min$

Fig. 3. Comparative assessment of blood sugar level of model objects of bread and glucose depending on time

The change in blood sugar over time after eating functional bread with FWP shows a slower digestion of carbohydrates in the studied foods and a moderate rise and fall in blood sugar compared to control samples.

The obtained research results indicate the functionality of the developed bakery product using FWP and can help patients with diabetes mellitus control sugar levels.

The results of studies of the developed functional bread with FWP allow us to propose it as correcting diabetic blood parameters, a promising enterosorbent in relation to lead compounds and to suggest their high sorbing effect in relation to other toxicants, including heavy metal ions.

Formulations and technologies of bakery products with the addition of FWP modification products in optimal ratios and proportions, characterized by increased nutritional value, have been developed.

Consumption of $100 \mathrm{~g}$ of the developed product with FWP powders will satisfy the daily need for dietary fiber by $40 \%$, which indicates the advisability of using powders of edible wild plants in the production of functional bread.

\section{Conclusion}

Thus, the life quality against the background of a declining level of human health under the existing conditions of ecological relapse, economic crisis can be improved by enriching food with such biological factors as protective, macro- and micronutrient, etc.

The use of food wild plants: flowers of white acacia, red clover leaves, sweet clover leaves, sweet clover flowers, red clover inflorescences in the development of functional flour products, due to its biochemical properties, is promising for regulating the polysaccharide composition of the final product and will allow realizing the biological potential for the purpose of the nation's healthier indicator.

The indicated herbal ingredients can be considered as an essential resource in the food space of the Republic of North Ossetia - Alania for the technology of functional food products, including bread, while significant contributions are not required for their extensive and rational use. 


\section{References}

1. Atlas of Medicinal Plants of Russia, 890 (All-Russian Scientific Research Institute of Medicinal and Aromatic Plants, 2006)

2. V.I. Vernadsky, Biosphere, 8 (1972)

3. M.B. Liga, I.A. Shchetkina, Quality of life: organizational and managerial aspect, 5-6 (2011)

4. V.V. Sadovoy, T.V. Shchedrina, V.V. Melentyeva, A.S. Khamitsaeva, Research Journal of Pharmaceutical, Biological and Chemical Sciences, 9(4), 1620 (2018)

5. V.V. Sadovoy, I.A. Trubina, T.V. Shchedrina, E.A. Skorbina, Research Journal of Pharmaceutical, Biological and Chemical Sciences, 8(1), 8925 (2017)

6. V.V. Sadovoy, M.A. Selimov, T.V. Slichedrina, A.A. Nagdalian, Research Journal of Pharmaceutical, Biological and Chemical Sciences, 7(5), 1861 (2016)

7. Sanpin 2.3.2.10 78-01, Hygienic requirements for the safety and nutritional value of food products, Ministry of Health of Russia, 165 (2002)

8. E.A. Strupan, V.S. Kolodyaznaya, O.A. Strupan, Bulletin of the Krasnoyarsk State Agrarian University, 7, 161 (2020)

9. V.A. Tutelyan, V.A. Knyazhev, Nutrition issues, 3, 4 (2003)

10. A.M. Ugolev, Theory of adequate nutrition and trophology, 8-12 (1991)

11. A.S. Khamitsaeva, Development of theoretical foundations and development of technologies of flour and meat products using the products of modification of vegetable raw materials, 71-77 (2011)

12. A.S. Khamitsaeva, Z.A. Khortiev, Prospects for the development of the agroindustrial complex in modern conditions, Materials of the 9th International Scientific and Practical Conference, 411 (2020)

13. A.S. Khamitsaeva, A.S. Tsarueva, Z.A. Khortiev, Kupat production method, Patent No. 2663069 (2018)

14. N.A. Khloyan, I.A. Ephieva, Bulletin of scientific works of young scientists, graduate students and masters, Mountain State Agrarian University, 126 (2019) 